\title{
$\beta$-Casein-phospholipid monolayers as model systems to understand lipid-protein interactions in the milk fat globule membrane
}

\author{
Sophie Gallier ～， Derek Gragson , Rafael Jiménez-Flores , David W. Everett
}

\begin{abstract}
A B S T R A C T
Phospholipid-protein monolayer films were studied as model systems to mimic the structure of the native bovine milk fat globule membrane (MFGM) and to understand lipid-protein interactions at the surface of the globule. Phospholipids extracted from bovine raw milk, raw cream, processed milk and buttermilk powder were spread onto the air-water interface of a Langmuir trough, $\beta$-casein was then added to the sub-phase, and Langmuir-Blodgett films were studied by epifluorescence microscopy and atomic force microscopy. In all films, $\beta$-casein was responsible for clustering of the sphingomyelin- and cholesterol-rich microdomains into larger platforms. This suggests that the same phenomenon may happen at the surface of the milk fat globule, where specific MFGM proteins may cause aggregation of microdomains.
\end{abstract}

\section{Introduction}

The lipid bilayer of biomembranes, such as the membranes surrounding biological cells, is seen as two weakly associated monolayers of phospholipids, embedding membrane proteins and cholesterol (Möhwald, 1990). Lipid packing leads to topographic nanometer-level height differences that can be detected by atomic force microscopy (AFM), which directly maps changes in packing density (Goksu, Vanegas, Blanchette, Lin, \& Longo, 2009). The liquid-ordered phase (also called a lipid raft), rich in sphingomyelin and cholesterol, and tightly packed, contains an increased trans/ gauche ratio making it, and its domains, thicker than the surrounding liquid-disordered phase that is rich in unsaturated phospholipids and more loosely packed (Simons \& Vaz, 2004). The size of lipid rafts is in the range of $10-200 \mathrm{~nm}$; however, larger domains, resulting from the association of small domains and considered to be more stable, may exist (Pike, 2006). Association of proteins with lipid rafts induces signalling in cells by either clustering small rafts or inducing formation of rafts in homogeneous bilayers previously without rafts (Brown \& London, 1998). Several cases of lipid raft clustering induced by protein polymerization, oligomerization or cross-linking have been reported (Simons \& Vaz, 2004). One key issue is how proteins associate with lipid rafts.

Two notions have been suggested to explain the structure of biological membranes: lipid-lipid interactions compartmentalize the membrane where the proteins arrange according to lipid domain affinity, or lipid-protein interactions are responsible for the formation of lipid domains around the membrane proteins (Poveda, Fernández, Encinar, \& Gonzalez-Ros, 2008). A more realistic picture of the arrangement of membrane components might include both lipid-lipid and lipid-protein interactions. The lipidlipid interactions lead to lipid domain formation that may be perturbed and changed by the presence of proteins. Oligomerization of membrane proteins and matching of hydrophobic regions between lipids and proteins play a role in domain formation (Poveda et al., 2008).

In any milk of mammalian origin, a specific trilayered biomembrane exists, namely the milk fat globule membrane (MFGM). This MFGM, keeping the fat globules in suspension, is mainly composed of proteins and phospholipids (Michalski, Michel, Sainmont, \& Briard, 2002). Its composition has been thoroughly studied; however, its structure is still poorly understood. The lateral heterogeneous distribution of the phospholipids and glycosylated molecules at the surface of the MFGM has been examined by confocal laser scanning microscopy (Evers et al., 2008; Gallier, Gragson, Jiménez-Flores, \& Everett, 2010b; Lopez, Madec, \& Jiménez-Flores, 2010). By this technique, lipid microdomains on the surface of the MFGM and protein association with the MFGM 
upon processing of milk were observed (Gallier et al., 2010b). Therefore, phospholipid-protein monolayer model systems appear to be suitable simplified model of the MFGM structure to investigate lipid-protein interactions and lipid domain formation at the surface of milk fat globules.

$\beta$-Casein monolayers at the air-interface have been structurally and morphologically characterized by Patino, Sánchez, and Niño (1999). Niño, Sánchez, and Patino (1999) investigated the interfacial characteristics of $\beta$-casein monolayers at the air-water interface as a function of temperature and pH. Caro, Niño, and Patino (2009a) studied the penetration of $\beta$-casein into a dipalmitoylphosphatidylcholine (DPPC) monolayer as a function of $\mathrm{pH}$, and the history of the spread of the DPPC monolayer (Caro, Niño, \& Patino, 2009b).

At $\mathrm{pH} 5$ and $\mathrm{pH} 7$, a $\beta$-casein monolayer collapses at the equi-

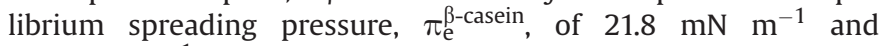
$20.9 \mathrm{mN} \mathrm{m}^{-1}$ respectively (Patino et al., 1999). By studying the adsorption of $\beta$-casein onto latex particles, the protein layer thickness was determined to be up to $15 \mathrm{~nm}$ (Horne \& Leaver, 1995). Even though $\beta$-casein monolayers have been proved to be relatively thin (Caro et al., 2009b), its thickness is maximal above the critical surface pressure and more compact in acidic sub-phases (Patino et al., 1999).

Using a Langmuir trough mounted on the stage of an epifluorescence microscope, and with the addition of a fluorescent probe to the lipid model system, phase separation is readily visualized (Gallier, Gragson, Jiménez-Flores, \& Everett, 2010c). In this study, the partitioning of $\beta$-casein between the liquid-ordered and the liquid-disordered phases of supported monolayers of natural complex mixtures of phospholipids extracted from raw milk (RM), raw cream (RC), processed milk (PM) and buttermilk powder (BP) was examined after sub-phase addition of the protein. The mixtures of phospholipids from the four dairy products are representative of the phospholipid composition found in the milk fat globule membrane at different stages of milk processing (Gallier, Gragson, Cabral, Jiménez-Flores, \& Everett, 2010a). It is essential to investigate if the proteins adsorb at the interface as a separate protein monolayer and therefore exist in protein domains without lipids, or if the proteins associate with the lipids and therefore penetrate the lipid domains. Understanding the interfacial structure is necessary as it is involved in cell signalling (Brown \& London, 1998), lipolysis phenomena during gastrointestinal digestion (van Aken, 2010; Golding et al., 2011), and interactions with the food matrix during manufacture of dairy products (Ong, Dagastine, Kentish, \& Gras, 2010).

\section{Materials and methods}

\subsection{Samples and reagents}

Bovine raw milk was collected from the bulk tank of milk from the dairy herd at the Dairy Products Technology Center (California Polytechnic State University, San Luis Obispo, CA, USA). Processed whole milk, pasteurized at $76^{\circ} \mathrm{C}$ for $15 \mathrm{~s}$ and homogenized at $14 \mathrm{MPa}$ in the first stage and $10 \mathrm{MPa}$ in the second, was bought from Producers Dairy Foods, Inc. (Fresno, CA, USA). Buttermilk powder was provided by Land O'Lakes, Inc. (Arden Hills, MN, USA). The phospholipid mixtures from RM, RC, PM and BP were obtained as described in Gallier et al. (2010a). The phospholipid extracts and the physical properties of the phospholipid monolayers were characterized in previous publications (Gallier et al., 2010a,c). The main findings were smaller amounts of phosphatidylcholine and sphingomyelin and a corresponding decrease in the saturation level in RC phospholipid extracts, and a considerably smaller amount of phosphatidylethanolamine in BP phospholipid extracts. $\beta$-Casein
(BioUltra, essentially salt-free, $\geq 98 \%$ from PAGE analysis) was purchased from Sigma-Aldrich Corp. (St. Louis, MO, USA) and stored at $-20{ }^{\circ} \mathrm{C}$. Chloroform and methanol (Fisher Scientific, Pittsburgh, PA, USA) were of HPLC grade. The fluorescent head group-labeled phospholipid analog Texas Red ${ }^{\circledR} 1,2$-dihexadecanoylsn-glycero-3-phosphoethanolamine, triethylammonium salt (Texas Red $^{\circledR}$-DHPE, $0.1 \mathrm{~mL}$ per $\mathrm{mL}$ of chloroform; Invitrogen, Molecular Probes, Carlsbad, CA, USA) provided contrast between lipid phases under an epifluorescence microscope. Milli-Q water $(18 \mathrm{M} \Omega \mathrm{cm}, \mathrm{pH}$ 5.5-6.5) used as the sub-phase was purified by means of a Millipore filtration device (Millipore Corporation, Bedford, MA, USA). Glass microscopic slides (Fisher Scientific) were cleaned by sonication for $30 \mathrm{~min}$ in the detergent Liqui-Nox (Structure Probe, Inc., West Chester, PA, USA) and then rinsed with Milli-Q water followed by a sonication for $10 \mathrm{~min}$ in methanol. The slides were dried with argon and finally placed for 20 min in a PDC 32 G-2 argon plasma cleaner (Harrick Plasma, Ithaca, NY, USA). Olympus OMCL-AC160TS aluminium coated silicon cantilevers (nominal force constant = $42 \mathrm{~N} \mathrm{~m}^{-1}$, nominal resonant frequency $=300 \mathrm{kHz}$, tip radius $=$ $9 \pm 2 \mathrm{~nm}$, Olympus Corporation, Center Valley, PA, USA) were used for alternating current $(A C)$ mode imaging.

\subsection{Langmuir-Blodgett films}

Fluorescence microscopy was used to examine phase separation within phospholipid-protein monolayer films deposited onto an air-water interface. A Minitrough Langmuir film balance (KSV Instruments, Helsinki, Finland) with a Wilhemy plate was mounted on an Olympus BX60 microscope. An Olympus QColorA mercury lamp served as a radiation source. Incident light was passed through an excitation filter to select wavelengths ranging from 510 to $590 \mathrm{~nm}$. Texas $\operatorname{Red}^{\circledR}$-DHPE, was used as the fluorescent dye at a concentration of $2 \%$ of the total phospholipid content by mass. At low concentration, the dye does not introduce significant perturbations to the membrane system (Möhwald, 1990). The phospholipid mixtures were dissolved in chloroform to a concentration of $1 \mathrm{mg} \mathrm{mL}^{-1}$ and $\beta$-casein was diluted to $1 \mathrm{mg} \mathrm{mL}^{-1}$ in PBS buffer ( $\mathrm{pH}$ 7.2). A precisely known volume (about $40 \mu \mathrm{L}$ in general to reach an initial surface pressure of about $6 \mathrm{mN} \mathrm{m}^{-1}$ ) of each phospholipid mixture was spread carefully onto the surface with a gastight microsyringe at $20{ }^{\circ} \mathrm{C}$ and the solvent was allowed to evaporate over 5 min $\beta$-Casein $(100 \mu \mathrm{L})$ was then added to the sub-phase with a gastight microsyringe. The sub-phase addition of $\beta$-casein to the phospholipid monolayer induced an increase in surface pressure of $0.1 \mathrm{mN} \mathrm{m}^{-1}$, which stabilized after $30 \mathrm{~min}$. The ratio of phospholipids to proteins used here was close to the ratio found in the native milk fat globule membrane. To allow for spreading, adsorption and rearrangement of the protein at the interface, 30 min was allowed to elapse and the film was subsequently compressed up to $20 \mathrm{mN} \mathrm{m}^{-1}$ (for RM and RC films) or up to $25 \mathrm{mN} \mathrm{m}^{-1}$ (for BP and PM films) and then transferred to a clean glass microscopic slide previously immersed into the sub-phase by lifting the support at a constant speed of $5 \mathrm{~mm} \mathrm{~min}^{-1}$. The LB film slides were stored in the dark in a temperature $\left(19^{\circ} \mathrm{C}\right) /$ humidity controlled room. The features observed with AFM and fluorescence microscopy did not change even after one year.

Bos and Nylander (1996) reported the squeezing-out of proteins from phospholipid monolayer films upon compression above the equilibrium spreading pressure of a pure $\beta$-casein monolayer. Therefore the protein-phospholipid films were analyzed with an AFM at a pressure slightly higher than $\pi_{\mathrm{e}}^{\beta \text {-casein }}$ to minimize the squeezing-out of the proteins, but high enough to observe large liquid-ordered domains and beyond formation of a 2D-foam structure as observed in previous work (Gallier et al., 2010c). The surface pressure of biological membranes is believed to be between 
30 and $35 \mathrm{mN} \mathrm{m}^{-1}$ (Demel, Geurtsvankessel, Zwaal, Roelofsen, \& Vandeenen, 1975). Reaching such a high pressure could lead to squeezing most of the proteins out of the monolayer film. Thus, the preparation of Langmuir-Blodgett (LB) films in this study was carried out at $20 \mathrm{mN} \mathrm{m}^{-1}\left(\pi<\pi_{\mathrm{e}}^{\beta \text {-casein }}\right)$ or $25 \mathrm{mN} \mathrm{m} \mathrm{m}^{-1}$ $\left(\pi>\pi_{\mathrm{e}}^{\beta \text {-casein }}\right)$. Also, at $25 \mathrm{mN} \mathrm{m}^{-1}$, it was more likely to observe sufficiently large domains in the BP films. Each phospholipidprotein film was analyzed by Langmuir trough combined with epifluorescence microscopy in triplicate, and each LangmuirBlodgett film was prepared in duplicate.

\subsection{Atomic force microscopy}

An MFP-3D atomic force microscope (Asylum Research, Santa Barbara, CA, USA) was used to image, in air, the surface of the phospholipid-protein monolayer films using AC mode to reduce lateral interactions between the surface and the probe tip. The whole system was isolated with an AEK 2002 acoustic enclosure (Herzan LLC, Laguna Hills, CA, USA) to optimize its performance and reduce environment noise and vibration. The images were processed using Igor Pro 6.05 software (Wavematrics Inc., Portland, OR, USA) and the proprietary MFP-3D software (Asylum Research) with a second order planefit and first order flatten. All scanning was carried out at $19^{\circ} \mathrm{C}$.

\section{Results}

\subsection{Formation of phospholipid-protein monolayers}

The sub-phase addition of $\beta$-casein to a clean water surface caused a gelation phenomenon (Fig. 1), indicating the adsorption of the protein at the air-water interface. This interfacial gelation is a common part of the three kinetic steps of adsorption of a protein to an aqueous surface (Caro et al., 2009b); the protein first diffuses onto the interface, then penetrates and unfolds at the interface and finally rearranges into an interfacial layer or multilayer, or gelation occurs. The spreading of the phospholipids on a protein film is a common technique to study protein-phospholipid films (Caro et al., 2009a; Patino, Fernández, Niño, \& Sánchez, 2006); however, due to the gelation phenomenon, even after compression-expansion-compression cycle, some large non-stained protein areas (Fig. 1A) and supposedly protein-branching areas (Fig. 1B) were observed in the protein-lipid films when first spreading the protein. This indicates that the mixing of the protein with phospholipids was not complete. The same dark stripes of proteins (Fig. 1A) were observed by Brewster angle microscopy after spreading proteins on a phospholipid monolayer (Roux, Baumberger, Axelos, \& Chardot, 2004). The method of first spreading the phospholipids onto the aqueous interface and then adding the protein to the sub-phase was thus preferred in this experimental study, an approach also used by Caro et al. (2009b).

\subsection{Langmuir-Blodgett films}

\subsubsection{Compression isotherms of phospholipid-protein monolayers}

Compression isotherms of phospholipid-protein monolayers (Fig. 2: BP and RM; RC and PM: results not shown) were recorded. The variations between the two compression isotherms can be related to the differences in phospholipid composition, mainly a lower amount of phosphatidylethanolamine and higher degree of saturation in the BP phospholipids (Gallier et al., 2010a,c). A slight inflection point (Fig. 2) on the compression isotherms of BP phospholipid- $\beta$-casein and RM phospholipid- $\beta$-casein films was present at surface pressures slightly above the equilibrium spreading pressure of $\beta$-casein. The same phenomenon was observed for RC and PM phospholipid-protein films (results not shown). This inflection point was also observed by Bos and Nylander (1996), who studied phospholipid- $\beta$-lactoglobulin monolayers, and Niño, Caro, and Patino (2009), who investigated phospholipid- $\beta$-casein monolayers, and was attributed to the "squeezing-out" of some proteins from the interface. This inflection point was absent in the compression isotherms of phospholipid monolayers from the four dairy products (Gallier et al., 2010c), as the phospholipid extracts did not contain any protein.

\subsubsection{Epifluorescence microscopic images of phospholipid- $\beta$ - casein monolayers}

The fluorescence microscopic images of the LB BP phospholipid- $\beta$-casein films (results not shown) did not show any specific features or differences from the BP phospholipid films (Gallier et al., 2010c). The LB PM phospholipid- $\beta$-casein films (Fig. 3A) showed liquid-ordered domains with flower shapes of 5-15 $\mu \mathrm{m}$ in size that were not observed in PM phospholipid films (Fig. 3B). These flower-shaped domains (Fig. 3A) were more stretched, larger and more numerous than the few observed in the PM phospholipid films (Fig. 3B). In the LB RC phospholipid- $\beta$-casein films (Fig. 3C), the large flower-shaped domains of $5-15 \mu \mathrm{m}$ in size seemed to be the result of aggregation of smaller domains linked by linearly branched molecules. These specific shapes were not observed in the LB RC phospholipid films (Fig. 3D). Fig. 3C shows
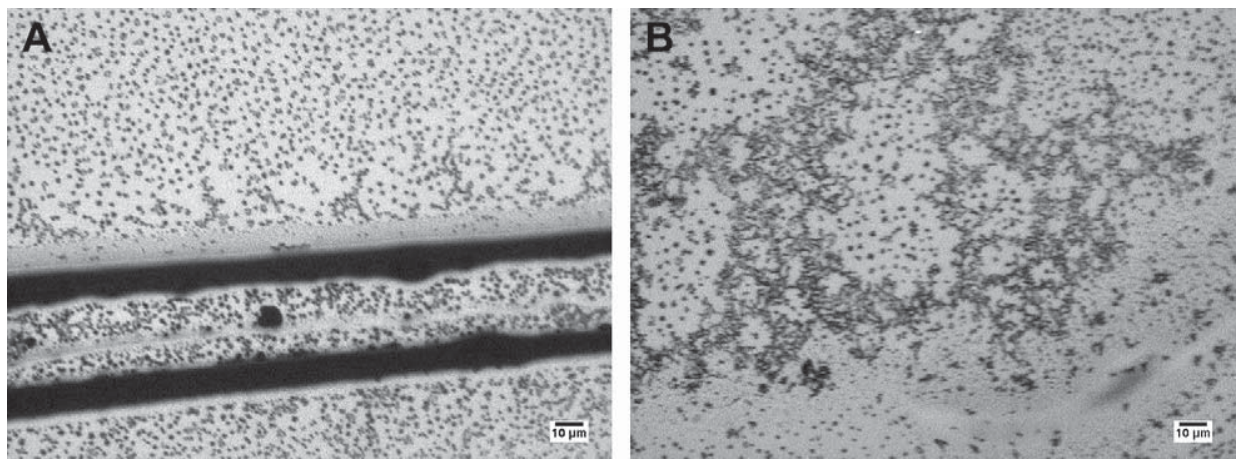

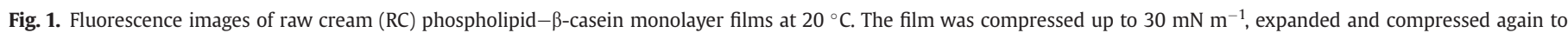

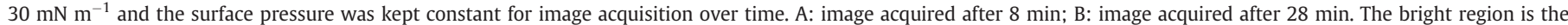

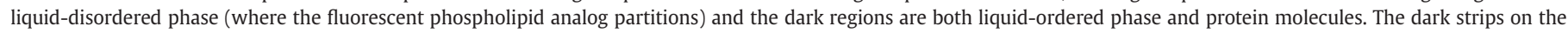
image $\mathrm{A}$ and the branched network on the image B are due to the presence of proteins. Scale bar $=10 \mu \mathrm{m}$. 


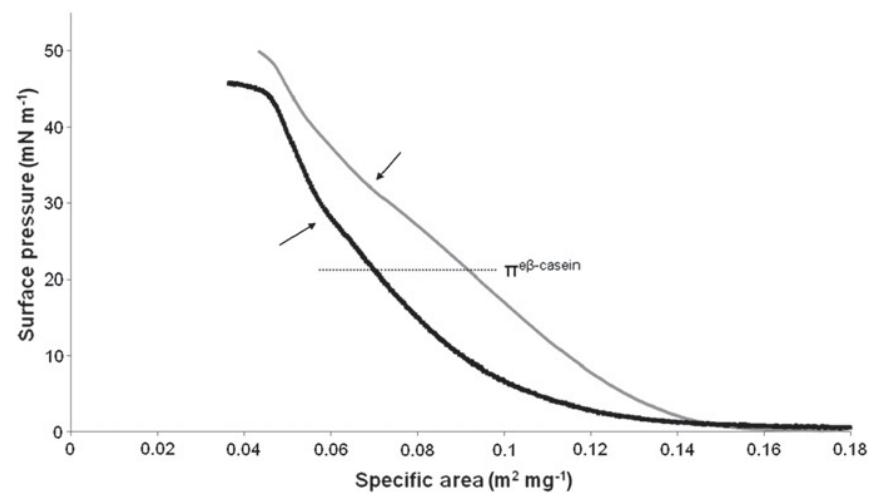

Fig. 2. Compression isotherms of (-) buttermilk powder (BP) phospholipid- $\beta$ casein and (_) raw milk (RM) phospholipid- $\beta$-casein monolayers at $20{ }^{\circ} \mathrm{C}$. Arrows point at inflection points. aggregation of domains by branched molecules similar to that observed in AFM images (Fig. 7). In the LB RM phospholipid- $\beta$-casein films (Fig. 3E), large flower-shaped domains of up to $20 \mu \mathrm{m}$ in size were also observed. These also seemed to originate from the aggregation of several lipid domains and were more stretched than the liquid-ordered domains observed in the LB RM phospholipid films (Fig. 3F).

After addition of protein to the lipid system, only the impact of the protein on the lipid domain properties is observable as the protein could not be stained efficiently, thus the exact location still remains unknown. Therefore, the use of AFM provides complementary data to understand protein-lipid interactions in native and model membrane systems. LB films were subsequently prepared and imaged with an AFM, differentiating the proteins from the lipids according to their height.

\subsection{AFM imaging of phospholipid-protein monolayers}

In the BP phospholipid- $\beta$-casein films, the size of the $\beta$-casein molecules varied (Fig. 4). This can be related to their shape, and
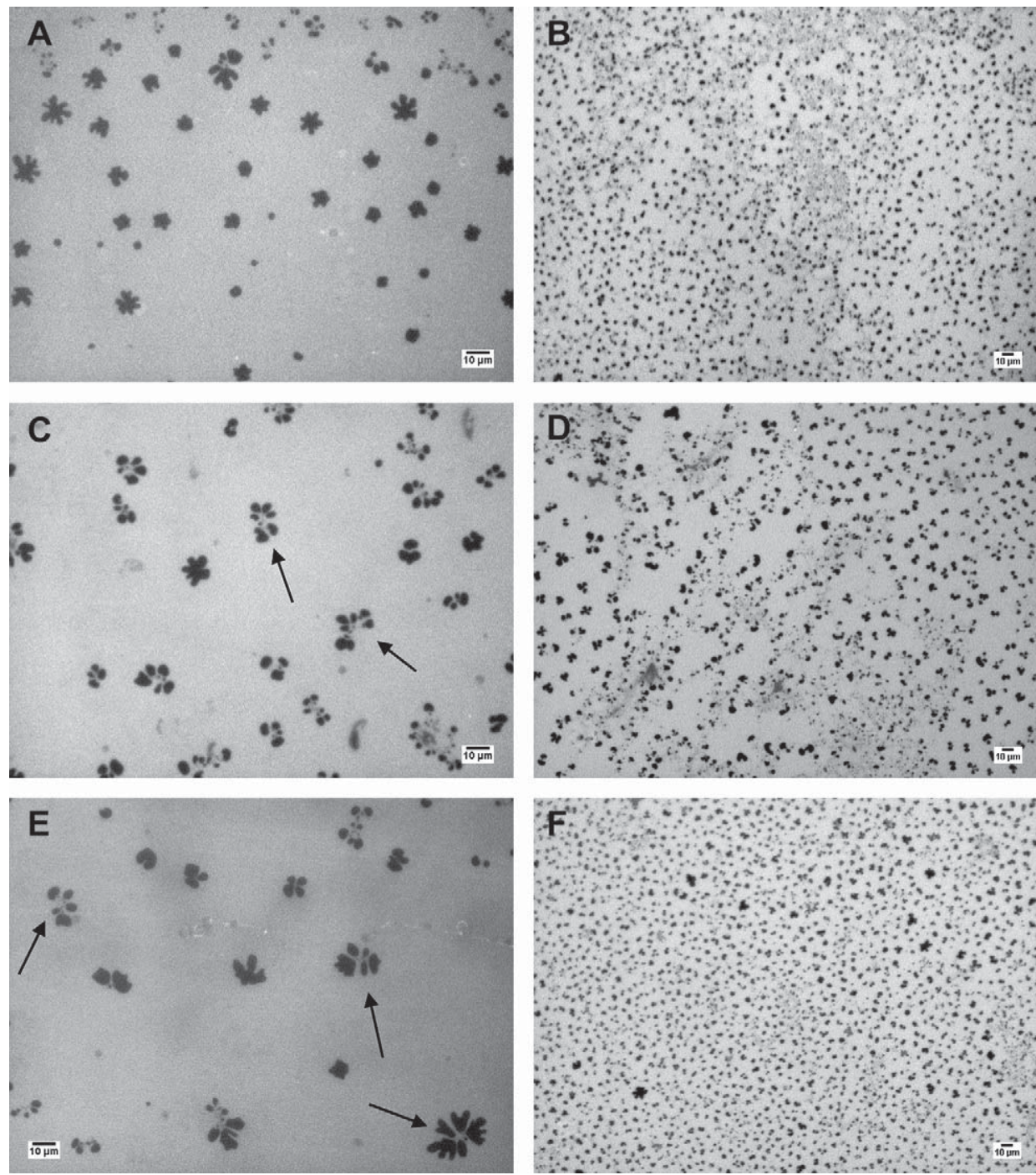

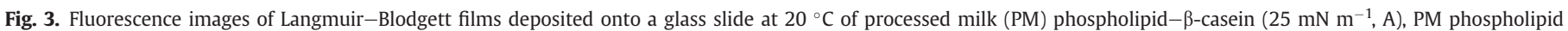

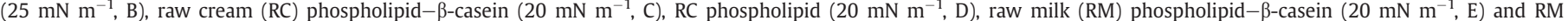

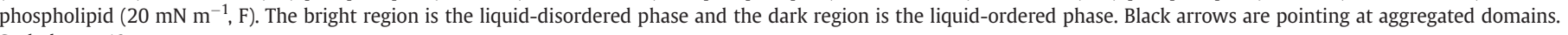
Scale bar $=10 \mu \mathrm{m}$ 
A
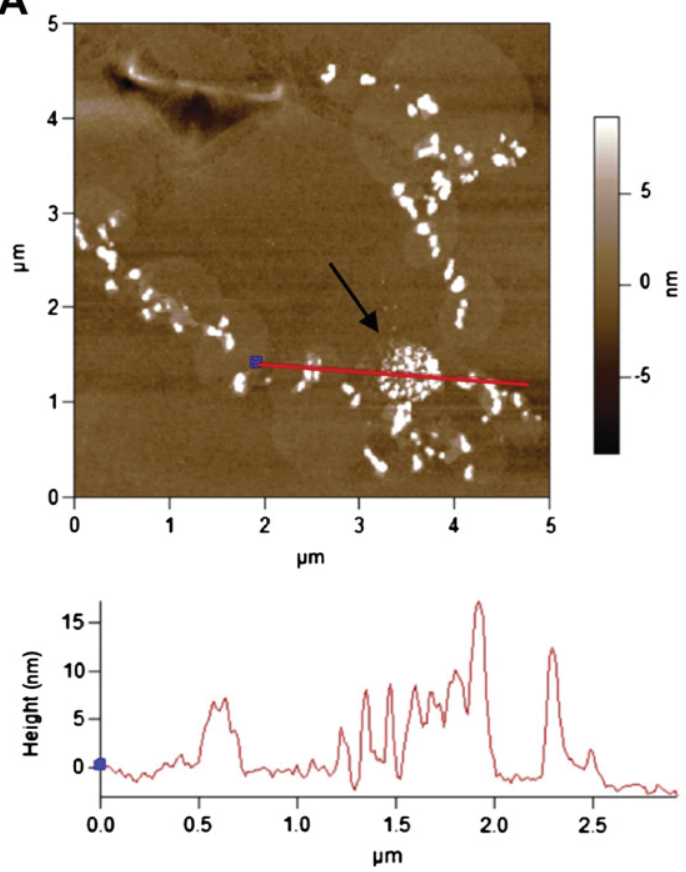

B
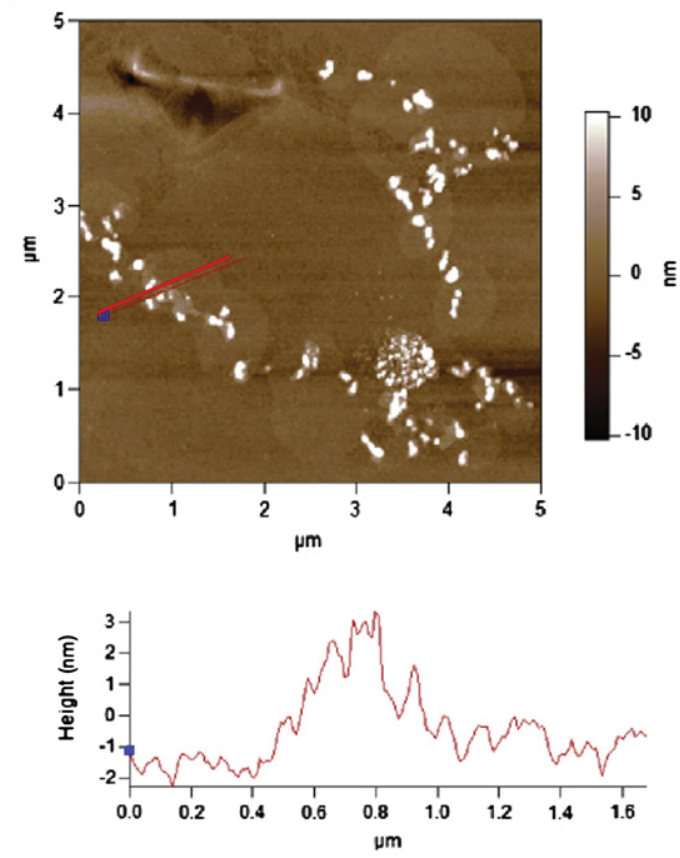

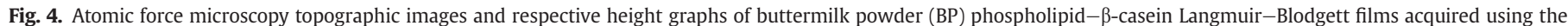

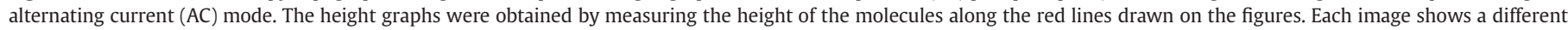

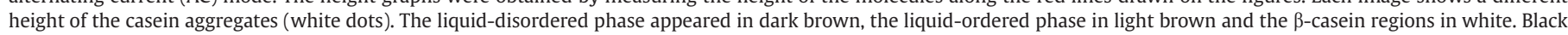
arrow is pointing at a casein micelle-like aggregate. (For interpretation of the references to colour in this figure legend, the reader is referred to the web version of this article.)

protein-protein interactions, as $\beta$-casein molecules tend to associate with each other to form micelle-like aggregates, as seen in Fig. 4. In BP phospholipid- $\beta$-casein films, $\beta$-casein aggregates ranged from 3 to $15 \mathrm{~nm}$ in size (Fig. 4). Phase images give information about the mechanical properties of a surface. The phase

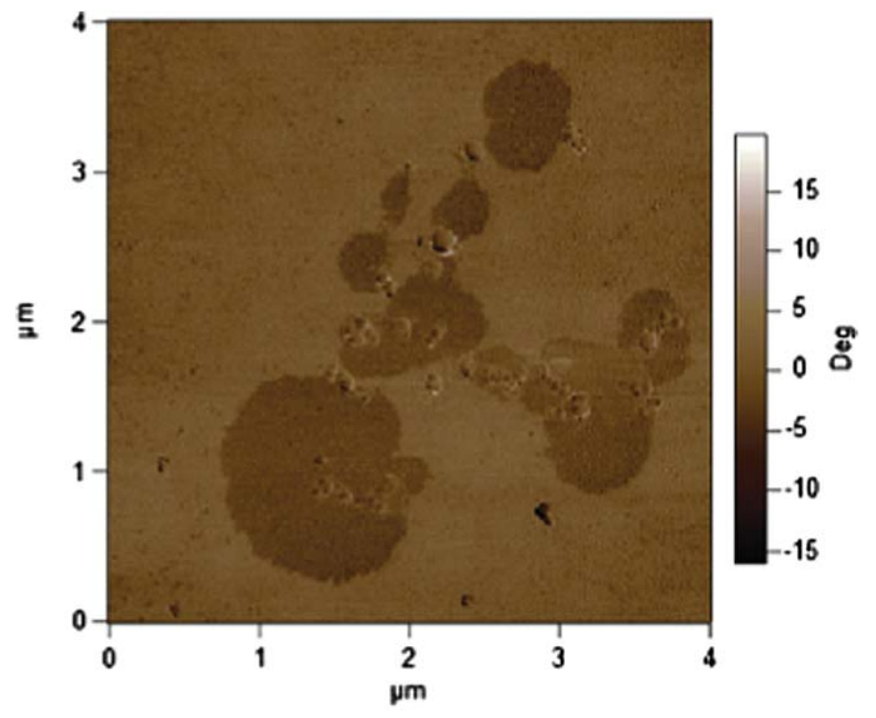

Fig. 5. Atomic force microscopy phase images of buttermilk powder (BP) phospholipid- $\beta$-casein Langmuir-Blodgett films acquired using the alternating current (AC) mode. The liquid-ordered phase appeared in dark brown, the liquid-disordered phase in light brown, and the $\beta$-casein regions appeared as light brown clusters. (For interpretation of the references to colour in this figure legend, the reader is referred to the web version of this article.) image of $\mathrm{BP}$ phospholipid- $\beta$-casein film was acquired in the repulsive AFM mode (Fig. 5); the liquid-ordered domains showed a smaller phase shift and thus are more rigid than the surrounding liquid-disordered domains.

The size of the $\beta$-casein molecules varied between 4 and $12 \mathrm{~nm}$ within the PM phospholipid- $\beta$-casein aggregate structure (Fig. 6), and the liquid-ordered domains were clustered by linearly branched $\beta$-casein molecules. The size of the $\beta$-casein molecules varied between 3 and $14 \mathrm{~nm}$ (Fig. 7) within the RC phospholipid$\beta$-casein aggregate. The $3 \mathrm{~nm}$ size may correspond to a single $\beta$-casein molecule forming a monolayer and the $14 \mathrm{~nm}$ size may correspond to the tail or several layers of $\beta$-casein molecules. Again, in the LB RC phospholipid- $\beta$-casein films (Fig. 7), $\beta$-casein formed a branched network clustering several liquid-ordered domains. The number of domains was variable and some domains seem to be traversed by fibrillar aggregates of $\beta$-casein molecules (Fig. 7B). The inverted height differences in the AFM images in Fig. 7 are due to a shift from the repulsive regime to the attractive regime using the AC mode (Roes, Seydel, \& Gutsmann, 2005).

In Fig. 8, clear branching of $\beta$-casein molecules aggregating together several liquid-ordered domains can be seen. In Fig. 8A, $\beta$-casein molecules were located inside, and on the edge of the liquid-ordered domains. When forming branches, the size of the $\beta$-casein molecules reached 3-4 nm (Fig. 8B) whereas, when located inside or on the edge of the lipid domains, they form aggregates or clusters of up to $30 \mathrm{~nm}$ (Fig. 8A). Similar protein aggregation within lipid rafts was reported by Saslowsky et al. (2002) after studying supported lipid-protein bilayers with AFM; the placental alkaline phosphatase (PLAP) formed dimers protruding from the elevated lipid rafts, however, larger protruding structures were associated with possible PLAP oligomers. Thus, the taller $\beta$-casein aggregates might be the result of oligomerization of $\beta$-casein molecules. 

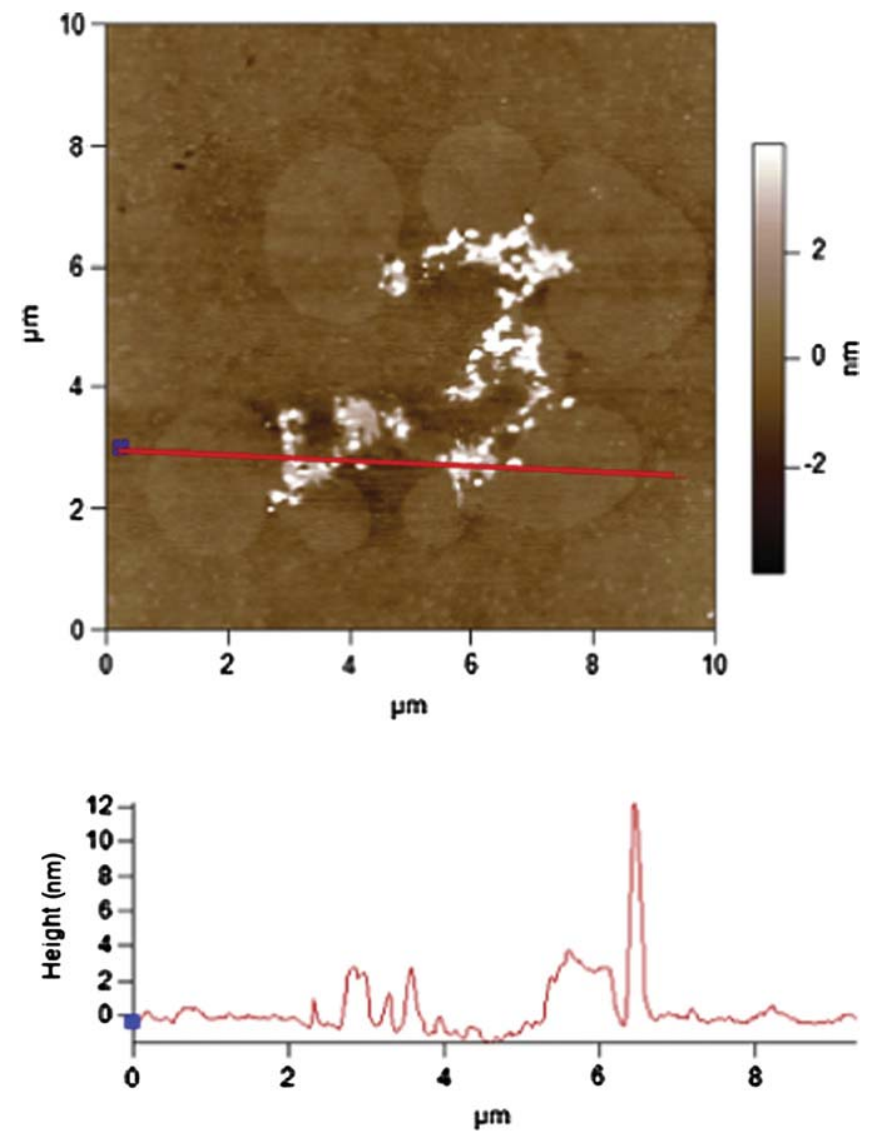

Fig. 6. Atomic force microscopy topographic image and respective height graph of processed milk (PM) phospholipid- $\beta$-casein Langmuir-Blodgett films acquired using the alternating current $(A C)$ mode. The height graph was obtained by measuring the height of the molecules along the red line drawn on the figure. The liquid-disordered phase appeared in dark brown, the liquid-ordered phase in light brown and the $\beta$-casein regions in white. (For interpretation of the references to colour in this figure legend, the reader is referred to the web version of this article.)

\section{Discussion}

It is interesting to note that the protein-phospholipid interactions also occurred above the collapse pressure of $\beta$-casein (Figs. 4-6). Caro et al. (2009b) studied the penetration of $\beta$-casein into a DPPC monolayer over-compressed up to $25 \mathrm{mN} \mathrm{m}^{-1}$ and determined that the topographic characteristics of the $\beta$-casein-phospholipid monolayer were dependent on the initial surface pressure of the DPPC monolayer and not on the final surface pressure after addition of $\beta$-casein and compression of the film. Patino et al. (2006) showed that, at a surface pressure $\pi>\pi_{\mathrm{e}}^{\beta \text {-casein }}, \beta$-casein was displaced from the $\beta$-casein-monoglyceride monolayer and that the interface was mainly occupied by monoglyceride molecules; the proteins remained underneath the monoglyceride monolayer either by local anchoring through the monoglyceride film or through hydrophobic interactions between $\beta$-casein and monoglyceride.

AFM images corroborate the structural polymorphism deduced from the isotherms for the phospholipid-protein monolayers and the respective epifluorescence images. Even though BP phospholipid (Gallier et al., 2010c) and BP phospholipid-protein (results not shown) monolayer films appeared differently than the other phospholipid (Gallier et al., 2010c) and phospholipid-protein (Fig. 3) monolayer films on the epifluorescence images, the AFM images of BP phospholipid-protein films (Figs. 4 and 5) revealed similar protein-lipid associations than in the other phospholipid-protein films (Figs. 6-8) on the AFM images. The flower-shaped domains observed in the phospholipid-protein LB films (Fig. 3) are the result of the interaction of $\beta$-casein with the phospholipids at the interface as seen in the AFM images (Figs. 6-8).

The structure and the composition of the absorbed material govern the physicochemical properties of an interfacial layer. Proteins and phospholipids are the main MFGM components, therefore it is relevant to study protein-phospholipid model systems that mimic the native MFGM. The $\beta$-casein molecules appeared as patched or as a branched molecular network recalling the fluorescence emission from the lectins revealing the heterogeneous location of MFGM glycolipids and glycoproteins (Lopez et al., 2010). $\beta$-casein may form linear structures either by oligomerization or cross-linking, and the same phenomenon may happen with glycoproteins on the surface of the MFGM. Emulsifier interactions at the interface of emulsion droplets influence the droplet stability, and rheological and textural properties of an emulsion. The interfacial supramolecular structure of the milk fat globules is affected by processing (Ong et al., 2010). For example, caseins interact with the MFGM during homogenization. According to the results above, caseins may adsorb at the surface of the globules via association with the liquid-ordered domains.

At $\mathrm{pH} 7, \beta$-casein has a small net negative charge located on the first $40-50$ amino acid residues, and the rest of the molecule is highly hydrophobic (Caro et al., 2007). Therefore not only electrostatic interactions of $\beta$-casein with phospholipid headgroups in monolayer systems (Caro et al., 2009a) must be considered, but also hydrophobic interactions between hydrophobic regions of the protein and the hydrocarbon chains of phospholipids. At $\mathrm{pH} 7$, electrostatic interactions are weaker than at $\mathrm{pH} 5$ due to an increase in the net negative charge of $\beta$-casein (Caro et al., 2007). Therefore the $\mathrm{pH}$ of the aqueous phase determines the importance of electrostatic interactions.

The free energy of the system is associated with the liberation of structured water molecules around hydrophobic regions of the phospholipids and the increased short-range van der Waals forces between these hydrophobic regions, such as the hydrocarbon chains in the phospholipids. A common picture for lipid domain genesis implies strong interactions between certain lipids and trans-membrane proteins. Attractive forces, such as strong electrostatic interactions and hydrogen bonding, arise from polar and charged amino acids and occur at the lipid head group and the protein interfacial region. Weaker forces such as Van der Waals and steric interactions occur in the trans-membrane region of the proteins and in the hydrophobic and interfacial area of the lipids (Poveda et al., 2008). Thus the formation of the flower domains may arise from a combination of electrostatic and hydrophobic interactions between $\beta$-casein and phospholipids. Unfortunately, with the complex mixture of phospholipids (Gallier et al., 2010a) used in this study, it is not possible to determine the specific phospholipids with which $\beta$-casein interacts. However, the BP phospholipid material contained a lower amount of phosphatidylethanolamine than the other phospholipid extracts, and the BP phospholipid$\beta$-casein films studied with epifluorescence microscopy (results not shown) were similar to the BP phospholipid films (Gallier et al., $2010 \mathrm{c})$, whereas the addition of $\beta$-casein to the other phospholipid films induced the formation of large liquid-ordered domains with flower shapes (Fig. 3). Therefore, phosphatidylethanolamine may be a key phospholipid in the interaction of liquid-ordered domains and $\beta$-casein.

A membrane can be seen as a solvent system, where each phase corresponds to a different solvent. The proteins have different solubility in each immiscible solvent and therefore will partition preferentially in one of the two solvents (representing the liquidordered and liquid-disordered phases) or at the domain line 


\section{A}
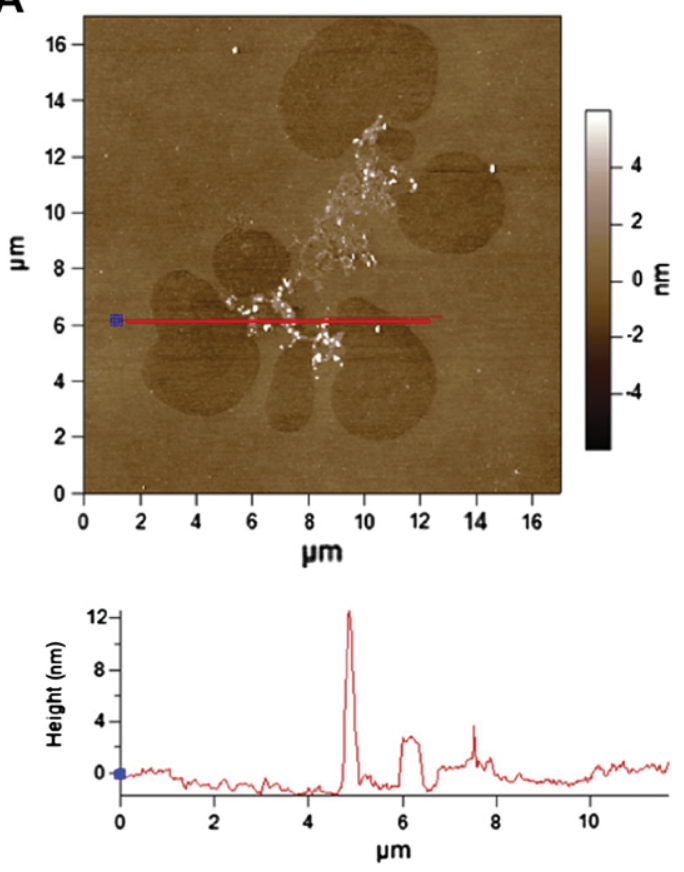

B
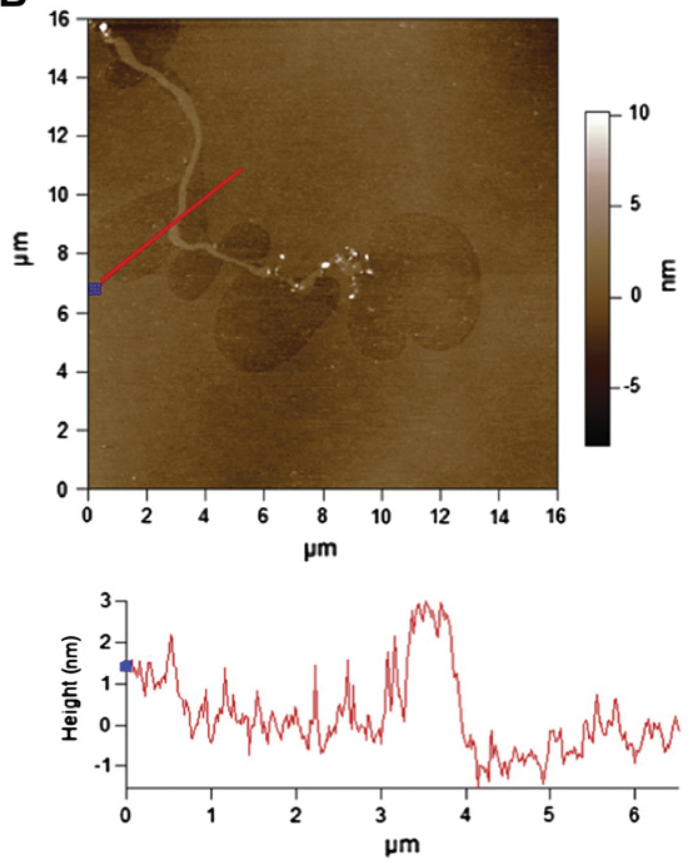

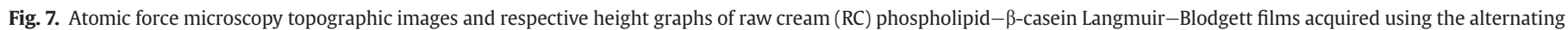

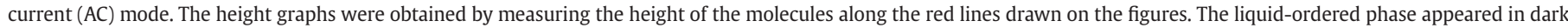

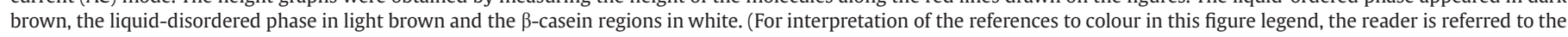
web version of this article.)

interface. The location of the membrane proteins is still unclear. Are they located inside the lipid rafts, and if so, how do they disturb the packing in liquid-ordered domains? Are they located at the lipid raft boundary where they may act as a surfactant and reduce the line tension at the interface? The position of specific proteins and/ or lipids at the raft boundary is very likely at liquid-liquid interfaces to reduce the large line tension in cell membranes (McConnell \& Vrljic, 2003).
A
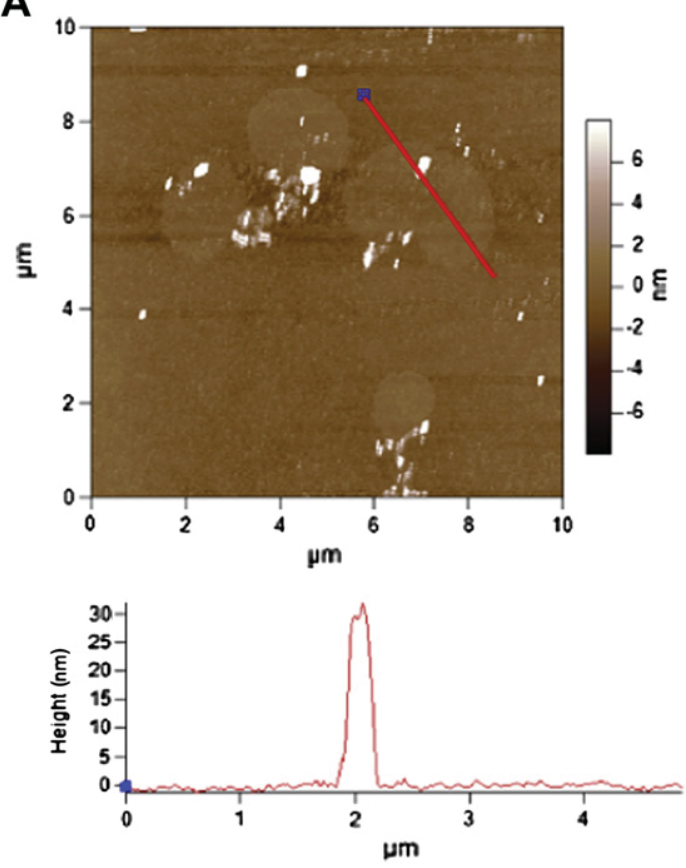

B
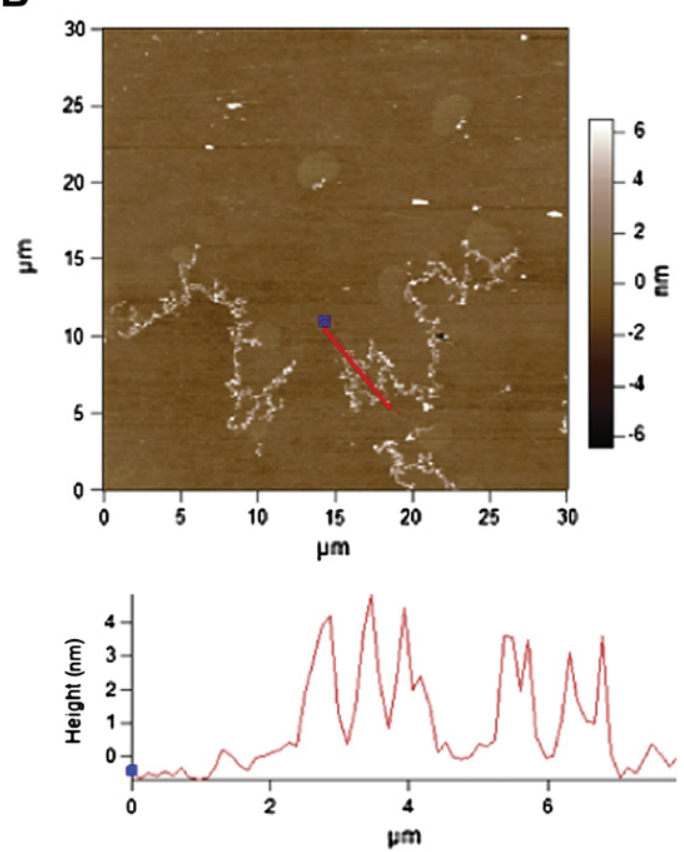

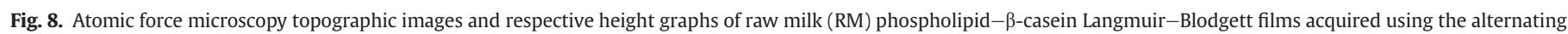

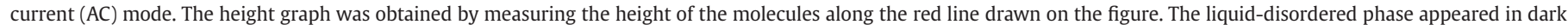

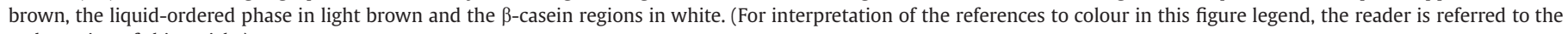
web version of this article.) 


\section{Conclusions}

$\beta$-Casein was mainly found associated with the liquid-ordered domains, revealing that at the interface, it does not exist in separate domains without lipids, but rather penetrates into the lipid domains or forms linear branches clustering the liquid-ordered domains. $\beta$-Casein caused aggregation or clustering of the liquidordered domains in all phospholipid films. The same protein-lipid interaction phenomenon may occur at the surface of milk fat globules; $\beta$-casein and other milk proteins, similar in physicochemical characteristics, could cluster liquid-ordered domains, leading to large, micrometer-scale lipid domains at the surface of the globules, as observed in our laboratory. Even though lipid-lipid interactions play a key role for phase separation within biological membranes, proteins affect the distribution of the lipid rafts and their function. Electrostatic and hydrophobic interactions may be the main driver for protein-lipid interactions in membrane systems.

\section{References}

van Aken, G. A. (2010). Relating food emulsion structure and composition to the way it is processed in the gastrointestinal tract and physiological responses: what are the opportunities? Food Biophysics, 5, 258-283.

Bos, M. A., \& Nylander, T. (1996). Interaction between beta-lactoglobulin and phospholipids at the air/water interface. Langmuir, 12, 2791-2797.

Brown, D. A., \& London, E. (1998). Functions of lipid rafts in biological membranes. Annual Review of Cell and Developmental Biology, 14, 111-136.

Caro, A. L., Mackie, A. R., Gunning, A. P., Wilde, P. J., Morris, V. J., Niño, M. R. R., et al. (2007). Role of electrostatic interactions on molecular self-assembly of protein plus phospholipid films at the air-water interface. Food Colloids: Self-Assembly and Material Science, 302, 227-243.

Caro, A. L., Niño, M. R. R., \& Patino, J. M. R. (2009a). Dynamics of penetration of dipalmitoyl-phosphatidyl-choline (DPPC) monolayers by [beta]-casein. Colloids and Surfaces A: Physicochemical and Engineering Aspects, 341, 134-141.

Caro, A. L., Niño, M. R. R., \& Patino, J. M. R. (2009b). Topography of dipalmitoylphosphatidyl-choline monolayers penetrated by beta-casein. Colloids and Surfaces A: Physicochemical and Engineering Aspects, 346, 146-157.

Demel, R. A. Geurtsvankessel, W. S. M., Zwaal, R. F. A., Roelofsen, B., \& Vandeenen, L. L. M. (1975). Relation between various phospholipase actions on human red-cell membranes and interfacial phospholipid pressure in monolayers. Biochimica Et Biophysica Acta, 406, 97-107.

Evers, J. M., Haverkamp, R. G., Holroyd, S. E., Jameson, G. B., Mackenzie, D. D. S., \& McCarthy, O. J. (2008). Heterogeneity of milk fat globule membrane structure and composition as observed using fluorescence microscopy techniques. International Dairy Journal, 18, 1081-1089.

Gallier, S., Gragson, D., Cabral, C., Jiménez-Flores, R., \& Everett, D. W. (2010a) Composition and fatty acid distribution of bovine milk phospholipids from processed milk products. Journal of Agricultural and Food Chemistry, 58, 10503-10511.
Gallier, S., Gragson, D., Jiménez-Flores, R., \& Everett, D. W. (2010b). Using confocal laser scanning microscopy to probe the milk fat globule membrane and associated proteins. Journal of Agricultural and Food Chemistry, 58, 4250-4257.

Gallier, S., Gragson, D., Jiménez-Flores, R., \& Everett, D. W. (2010c). Surface characterization of bovine milk phospholipid monolayers by Langmuir isotherms and microscopic techniques. Journal of Agricultural and Food Chemistry, 58, 12275-12285.

Goksu, E. I., Vanegas, J. M., Blanchette, C. D., Lin, W. C., \& Longo, M. L. (2009). AFM for structure and dynamics of biomembranes. Biochimica et Biophysica ActaBiomembranes, 1788, 254-266.

Golding, M., Wooster, T. J., Day, L., Xu, M., Lundin, L., Keogh, J., et al. (2011). Impact of gastric structuring on the lipolysis of emulsified lipids. Soft Matter, 7, 3513-3523.

Horne, D. S., \& Leaver, J. (1995). Milk-proteins on surfaces. Food Hydrocolloids, 9, 91-95.

Lopez, C., Madec, M.-N., \& Jiménez-Flores, R. (2010). Lipid rafts in the bovine milk fat globule membrane revealed by the lateral segregation of phospholipids and heterogeneous distribution of glycoproteins. Food Chemistry, 120, 22-33.

McConnell, H. M., \& Vrljic, M. (2003). Liquid-liquid immiscibility in membranes. Annual Review of Biophysics and Biomolecular Structure, 32, 469-492.

Michalski, M. C., Michel, F., Sainmont, D., \& Briard, V. (2002). Apparent zetapotential as a tool to assess mechanical damages to the milk fat globule membrane. Colloids and Surfaces B-Biointerfaces, 23, 23-30.

Möhwald, H. (1990). Phospholipid and phospholipid-protein monolayers at the air/ water interface. Annual Review of Physical Chemistry, 41, 441-476.

Niño, M. R. R., Caro, A. L., \& Patino, J. M. R. (2009). Structural, topographical, and rheological characteristics of beta-casein-dioleoyl phosphatidylcholine (DOPC) mixed monolayers. Colloids and Surfaces B-Biointerfaces, 69, 15-25.

Niño, M. R. R., Sánchez, C. C., \& Patino, J. M. R. (1999). Interfacial characteristics of beta-casein spread films at the air-water interface. Colloids and Surfaces B-Biointerfaces, 12, 161-173.

Ong, L., Dagastine, R. R., Kentish, S. E., \& Gras, S. L. (2010). The effect of milk processing on the microstructure of the milk fat globule and rennet induced gel observed using confocal laser scanning microscopy. Journal of Food Science, 75, E135-E145.

Patino, J. M. R., Fernández, M. C., Niño, M. R. R., \& Sánchez, C. C. (2006). Spreading of monoglycerides onto beta-casein adsorbed film. Structural and dilatational characteristics. Journal of Agricultural and Food Chemistry, 54, 3723-3732.

Patino, J. M. R., Sánchez, C. C., \& Niño, M. R. R. (1999). Structural and morphological characteristics of beta-casein monolayers at the air-water interface. Food Hydrocolloids, 13, 401-408.

Pike, L. J. (2006). Rafts defined: a report on the Keystone symposium on lipid rafts and cell function. Journal of Lipid Research, 47, 1597-1598.

Poveda, J. A., Fernández, A. M., Encinar, J. A., \& Gonzalez-Ros, J. M. (2008). Proteinpromoted membrane domains. Biochimica et Biophysica Acta-Biomembranes, $1778,1583-1590$.

Roes, S., Seydel, U., \& Gutsmann, T. (2005). Probing the properties of lipopolysaccharide monolayers and their interaction with the antimicrobial peptide polymyxin B by atomic force microscopy. Langmuir, 21, 6970-6978.

Roux, E., Baumberger, S., Axelos, M. A. V., \& Chardot, T. (2004). Oleosins of Arabidopsis thaliana: expression in Escherichia coli, purification, and functional properties. Journal of Agricultural and Food Chemistry, 52, 5245-5249.

Saslowsky, D. E., Lawrence, J., Ren, X. Y., Brown, D. A., Henderson, R. M., \& Edwardson, J. M. (2002). Placental alkaline phosphatase is efficiently targeted to rafts in supported lipid bilayers. Journal of Biological Chemistry, 277, 26966-26970.

Simons, K., \& Vaz, W. L. C. (2004). Model systems, lipid rafts, and cell membranes. Annual Review of Biophysics and Biomolecular Structure, 33, 269-295. 